\title{
Assessing Knowledge, Attitude, and Practices towards Ivermectin Pre-exposure Prophylaxis for COVID-19 among Health Care Workers
}

\section{Ajay Kumar Verma ${ }^{1}$, Anuj Kumar Pandey ${ }^{2}$, Arpita Singh ${ }^{3}$, Jyoti Bajpai ${ }^{4}$, Surya Kant ${ }^{5}$, Darshan Kumar Bajaj ${ }^{6}$}

${ }^{1}$ Additional Professor, Department of Respiratory Medicine, King George's Medical University, Lucknow, 226003, Uttar Pradesh, India; ${ }^{2}$ PHD Scholar, Department of Respiratory Medicine, King George's Medical University, Lucknow, 226003,Uttar Pradesh, India; ${ }^{3}$ Additional Professor, Department of Pharmacology, Dr. Ram Manohar Lohia Institute of Medical Sciences, Lucknow,226010, Uttar Pradesh, India; ${ }^{4}$ Assistant Professor, Department of Respiratory Medicine, King George's Medical University, Lucknow, 226003,Uttar Pradesh, India; ${ }^{5}$ Professor and Head, Department of Respiratory Medicine, King George's Medical University, Lucknow, 226003,Uttar Pradesh, India; ${ }^{6}$ Additional Professor, Department of Respiratory Medicine, King George's Medical University, Lucknow, 226003,Uttar Pradesh, India

\begin{tabular}{|c|c|c|c|c|c|c|c|}
\hline Abstract & Introduction & Methodology & Results & Conclusion & References & Citation & Tables / Figures \\
\hline \multicolumn{8}{|c|}{ orresponding Author } \\
\hline \multicolumn{7}{|c|}{$\begin{array}{l}\text { Dr. Ajay Kumar Verma, Additional Professor, Department of Respiratory Medicine, King George's Medical } \\
\text { University, Lucknow, 226003, Uttar Pradesh, India } \\
\text { E Mail ID: } \underline{\text { drajay21@gmail.com }}\end{array}$} & 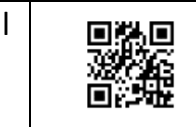 \\
\hline
\end{tabular}

\section{Citation}

Verma AK, Pandey AK, Singh A, Bajpai J, Kant S, Bajaj DK. Assessing Knowledge, Attitude, and Practices towards Ivermectin Pre-exposure Prophylaxis for COVID-19 among Health Care Workers. Indian J Comm Health. 2021;33(3):430-434. https://doi.org/10.47203/IJCH.2021.v33i03.004

Source of Funding: Nil Conflict of Interest: None declared

\section{Article Cycle}

Received: 20/07/2021; Revision: 10/08/2021; Accepted: 29/08/2021; Published: 30/09/2021

This work is licensed under a Creative Commons Attribution 4.0 International License.

\section{Abstract}

Background: Health care workers (HCWs) are more likely to be at high risk of SARS-CoV-2 infection due to their direct and/or indirect participation in treatment facilities. Here, we aimed to evaluate the knowledge, attitude, and practices of ivermectin pre-exposure prophylaxis (PEP) in HCWs. Materials and Methods: In this observational study HCWs who were directly/indirectly involved in the medication of COVID-19 patients were selected. The study questionnaire included demographic data; knowledge, attitudes, practices, and associated adverse drug reactions (ADR) after using ivermectin as pre-exposure prophylaxis in COVID-19. Results: The mean age of the selected 306 participants was 34.41 \{tstandard deviation 4.08\}. $66.66 \%$ of the participants were men. $15.69 \%$ of individuals had co-morbidities. HCWs were about COVID-19, and $94.12 \%$ of people know the role of ivermectin as PEP. Additionally, 180 participants (58.82\%) realized that ivermectin can cause adverse drug reactions (ADRs). $70.59 \%$ of the study-participants admitted that ivermectin has a protective effect on COVID-19, while $62.75 \%$ of the participants believed that the PEP benefits of using ivermectin outweigh the risks. $57.37 \%$ ( $n$ $=210)$ of HCW used ivermectin and completed the recommended medication process. Eighteen participants $(8.57 \%)$ experienced adverse reactions and reported to the ADR monitoring center. Conclusion: $70.59 \%$ of the studied participants agreed that ivermectin has a protective effect on COVID-19, and $57.37 \%$ of the participants have taken ivermectin as PEP. However, $8.57 \%$ of the individuals reported ADR, but none of the participants were severe enough to discontinue the drug.

\section{Keywords}

Adverse drug reaction; Ivermectin; Infection; Pandemic; SARS-CoV-2; RT-PCR; Pharmaceutical Preparations

\section{Introduction}

We are in the race with a novel coronavirus for survival. In the second wave of COVID-19 world is crying. The ongoing COVID-19 pandemic is the most destructive and difficult to control crisis ever experienced by the world. Millions of lives have been endangered, and many more people are still fighting from this critical situation with this virus, lurking in the atmosphere (1). However, there is no definite treatment available for COVID-19 till date. Several vaccines and medications are being developed, but are not sufficient to stop the pandemic. Although the search for an ideal medication and vaccine is still in progress, it is important for the scientific fraternity and doctors to find alternative sources of prevention using drugs that are already widely used (2).

Frontline health care workers (HCWs) viz doctors, residents, nurses, pharmacists, and other personnel have direct and/or indirect contact to SARS-CoV-2 infected 
patients. Because of repeated contact, they have a very high chance of being infected. Globally, medical staff managing COVID-19 patients are being infected, with an estimated range of $4.4 \%-20 \%$ (3-4). In this case, chemoprevention may reduce the infection rate of HCWs $(2,5,6)$. In pre-exposure prophylaxis (PEP), drugs/therapies can prevent this disease.

Ivermectin is a drug with a wide range of biological activities and has been used to treat human parasitic infections for many years. Some researches show that ivermectin has antiviral activity in-vitro towards the SARSCoV-2 virus (7). It is considered as a possible target drug for SARS-CoV-2 and is being studied in many clinical trials. Ivermectin may be a probable molecule which can be used as a prophylaxis and healing of people infected with SARSCoV-2. A group of senior medical practitioners from India met on 19th July 2020 under the aegis of the Academy of Advanced Medical Education for the management of COVID-19 and concluded that ivermectin can be a potential drug for prophylaxis and treatment of COVID-19 patients (8). The group had published a "white paper on ivermectin as a potential therapy for COVID-19" which was widely accepted and used in COVID-19 treatment facility. It was assumed that if health care professionals took ivermectin before exposure to the SARS-CoV-2 virus then their chances of getting an infection will be lowered and they can be protected from COVID-19.

\section{Aims \& Objectives}

1. To assess the demographic profile of health care professionals during COVID-19 pandemic.

2. To evaluate their knowledge, attitude \& practices towards ivermectin pre-exposure prophylaxis in COVID-19.

\section{Material \& Methods}

It was questionnaire based observational study. We have purposively selected HCWs from four government and three private hospital of Lucknow, Uttar Pradesh, India which were involved in COVID-19 managment. HCWs consisted of doctors, residents, research students, and other hospital staff (nurse, pharmacist, etc.) who were directly and/or indirectly involved in the COVID-19 hospitals were enrolled. The age group of participants was 21 to 60 years. We have approached via email to many participants. However, $339 \mathrm{HCW}$ s were responded. Out of 339 participants, 33 were incorrectly and/or incompletely filled the study questionnaire. Hence, we had selected 306 HCWs.

The study questionnaire consisted of demographic data such as age, gender, institution, health profession, comorbidity, and medication obtained from the health care workers. Knowledge, attitude, and practices of ivermectin pre-exposure prophylaxis, adverse drug reaction (ADR), and its reporting were also determined. Questionnaire was developed and validated with the help of experts in the field of respiratory medicine, and pharmacology. The study protocol was approved by the Institutional Ethics Committee of the institution.

Here, we had used study questionnaire in Google form to collect data. Google form was sent to the participants via email as at the surge of COVID-19 pandemic one-to-one meeting was avoided and was sometimes not possible/safe/suitable. Participants had answered questions by clicking the corresponding box or input content. On the first page of the questionnaire, all participants were informed of the confidentiality and anonymity of their answers. At the end all the entries were checked by the medical expert and completely filled questionnaire were selected to derive the results. Collected data were analysed by the SPSS software package (version 5, IBM, Germany) to get the significant results. Data were presented as mean \pm standard deviation (SD), number and percentage (\%).

\section{Results}

Demographic profile of Health Care Workers: The demographic profile of HCWs was depicted in [Table 1]. The age of $306 \mathrm{HCW}$ s was $34.41 \pm 4.08$ (mean \pm standard deviation). HCWs were categorized into age groups 21-30 $(n=102), 31-40(n=132), 41-50 \quad(n=60)$, and 51-60 ( $n=12)$. Total number of male participants $(n=204,66.7 \%)$ was more than females ( $n=102,33.3 \%$ ). Out of $306 \mathrm{HCWs,} 120$ doctors, 72 residents, 48 research students, and 42 hospital staff were enrolled [Figure 1]. 78.4\% participants were from government hospitals while the rest were from private hospitals and/or clinics. A total of $15.7 \%$ participants $(n=48)$ had associated with co-morbidities like hypertension, diabetes, high blood pressure, hypothyroidism, and asthma, etc. [Figure 2].

Assessment of knowledge: All HCWs have knowledge of COVID-19. When asked about their treatment options, $35.3 \%$ of the participants replied that so far, there is no treatment for COVID-19. 98\% of the subjects had heard of ivermectin, and $94 \%$ of the subjects knew the role of ivermectin in pre-exposure prevention in COVID-19. 96\% of HCW answered that ivermectin chemoprevention is in the experimental stage [Table 2].

Assessment of attitude: 270 (88.24\%) health care workers agreed that ivermectin should be used for pre-exposure prophylaxis (PEP) of COVID-19, while $70 \%$ of participants believed that ivermectin could prevent COVID-19. 41.18\% of HCP believe that because the drug is in the experimental stage, it will cause a false sense of security. It was asked to subjects that what they think about the benefit: risk ratio of using ivermectin (more benefit; more risk; not sure); $62.75 \%$ answered 'more benefit', more risk (3.92\%), and 'not sure' ticked by $33.33 \%$ participants [Figure 3]. In addition to this, 180 participants (58.82\%) realized that ivermectin can cause adverse drug reaction [Table 3].

Assessment of practice: The assessment of practice was presented in [Table 4]. 57.37\% $(n=210)$ of health workers 
have used ivermectin for pre-exposure prevention of COVID-19. Among the 210 participants, 198 (94.28\%) took the medication in time and completed the course of medication. $91.42 \%(n=192)$ of HCP did not report any ADR after using ivermectin. Eighteen participants (8.57\%) experienced ADR while using ivermectin. All these 18 participants have reported ADR to the Adverse Monitoring Center (AMC) or the National Coordinating Center of India-Pharmacovigilance Program (PvPI). None of the participants had to stop the PEP ivermectin regimen due to ADR. The main adverse reactions reported by participants were diarrhoea, abdominal pain, nausea, and loss of appetite [Figure 4].

\section{Discussion}

In the present study, we assessed the knowledge, attitude, and practice of HCWs especially doctors, resident doctors, research students, hospital staff (nurse, pharmacist, etc) towards ivermectin prophylaxis in COVID19. Our data shows that HCPs have basic knowledge of ivermectin prophylaxis. Their attitude towards the usage of ivermectin was also satisfactory. $57.37 \%(n=210)$ of health workers have used ivermectin as pre-exposure prophylaxis from COVID-19. Moreover, 91.42\% $(n=192)$ of HCP did not report any ADR after using ivermectin. Eighteen participants (8.57\%) experienced ADR while using ivermectin. The major adverse reactions reported by participants were diarrhea, abdominal pain, nausea, and loss of appetite. Collectively, results of present study are in favor of using ivermectin as prophylaxis in HCWs to diminish the COVID-19 infection.

Caly $L$ et al. demonstrated that within 48 hours of a single dose of $5 \mu \mathrm{M}$ ivermectin, it can inhibit SARS-CoV-2 in vitro, reducing viral RNA by $99.98 \%$ [9]. They believe that ivermectin can play a role by inhibiting IMP $\alpha / \beta 1$ mediated nuclear import of viral proteins (7). An observational study was performed to ascertain the ivermectin as PEP for COVID-19 among health care providers in the Dhaka and authors suggested that ivermectin could be used as a prophylaxis in COVID-19 (1). In addition to this, a randomized control trial study was performed to evaluate the safety and efficacy of ivermectin, hydroxychloroquine, and vitamin C as a chemoprophylaxis in COVID-19 (9). Authors had concluded that two-dose ivermectin $(300 \mu \mathrm{g} / \mathrm{kg}$ with a gap of 72 hours) reduced $73 \%$ of COVID19 infection in HCPs for the following month. Also, stated that types of households, COVID-19 duty, ivermectin single-dose, vitamin $C$, hydroxychloroquine were not linked with SARS-CoV-2 infection. A randomized clinical trial was conducted to investigate the ivermectin prophylaxis among HCWs in Egypt (10). Researchers had concluded that ivermectin was beneficial to avoid SARSCoV-2 infection without serious adverse effects and/or mortality in health workers. Contrary to the current work on the importance of ivermectin in the eradication of COVID-19, as previous studies showing the in vivo therapeutic efficacy of ivermectin (11); although in vitro studies have proved that the drug has a broad range of antiviral effects, Momekova $\mathrm{G}$ refused to consider that the drug has a broader range of antiviral effects (12).

As COVID-19 cases are continuously increasing in the whole world, it is difficult to estimate the actual number of infected people due to asymptomatic, no, and/or mild symptoms. In that case, it is essential to use a drug/therapy to overcome COVID-19 infection. Ivermectin is a safe, cheap, widely available drug, and proven antiviral activity may be used as prophylaxis in COVID-19.

\section{Conclusion}

Our data shows that $70.59 \%$ of the HCWs agreed that ivermectin has a protective effect on COVID-19, and $57.37 \%$ of the subjects have taken ivermectin as PEP. However, $8.57 \%$ of the individuals reported ADR, but none of the participants were severe enough to discontinue the drug. In addition to this, further research on large-scale clinical trials of ivermectin prophylaxis is also necessary.

\section{Limitation of the study}

In the present study data was collected from limited participants. Here, HCWs have not given ivermectin from single company, as it was questionnaire based study. Hence, further studies like randomized control trials with larger sample size are needed.

\section{Relevance of the study}

Ideal dose of ivermectin may be used to prevent SARSCoV-2 infection in frontline healthcare workers in COVID19.

\section{Authors Contribution}

All authors have contributed equally.

\section{Acknowledgement}

Authors are thankful to all the health care professionals who have participated in the study.

\section{References}

1. Alam M, RM P. Ivermectin as pre-exposure prophylaxis for COVID 19 among healthcare providers in a selected tertiary hospital in Dhaka an observational study. Eur J Med Health Sci. 2020;2:1-5.

2. Singh A, Kumar H, Gupta P, Verma AK, Kant S, Jain A, Pandey AK, Singh SK. Assessment of knowledge, attitude, and practices towards hydroxychloroquine pre-exposure prophylaxis among health care professionals. Indian J Comm Health. 2020;32(4):681687.

3. Guan WJ, Ni ZY, Hu Y, Liang WH, Ou CQ, He JX, et al. Clinical characteristics of coronavirus disease 2019 in China. New England journal of medicine. 2020;382(18):1708-20.

4. The Lancet. COVID-19: protecting health-care workers. Lancet. 2020;395(10228):922.

5. Remuzzi A, Remuzzi G. COVID-19 and Italy: what next? Lancet. 2020;395(10231):1225-1228.

6. Keeley AJ, Evans C, Colton H, Ankcorn M, Cope A, Bennett T, et al. Roll-out of SARS-CoV-2 testing for healthcare workers at a large NHS Foundation Trust in the United Kingdom, March 2020. Eurosurveillance. 2020;25(14):2000433.

7. Caly L, Druce JD, Catton MG, Jans DA, Wagstaff KM. The FDAapproved drug ivermectin inhibits the replication of SARS-CoV-2 in vitro. Antiviral Res. 2020; 178:104787. 
INDIAN JOURNAL OF COMMUNITY HEALTH / VOL 33 / ISSUE NO 03 / JUL-SEP 2021

8. Vora A, Arora VK, Behera D, Tripathy S. White paper on Ivermectin as a potential therapy for COVID-19. indian journal of tuberculosis. 2020 Jul 1;67(3):448-51.

9. Behera P, Patro BK, Singh AK, Chandanshive PD, S. R. R, Pradhan SK, et al. Role of ivermectin in the prevention of SARS-CoV-2 infection among healthcare workersin India: A matched case-control study. PLoS ONE.2021. 16(2): e0247163.

10. Shouman W. Use of Ivermectin as a Prophylactic Option in Asymptomatic Family Close Contact for Patient With COVID-19.
[Assessing Knowledge, Attitude...] | Verma AK et al clinicaltrials.gov Report No.: NCT04422561. Available from:https://clinicaltrials.gov/ct2/show/NCT04422561.

11. Heidary F, Gharebaghi R. Ivermectin: A systematic review from antiviral effects to COVID-19 complementary regimen. J Antibiot (Tokyo). 2020;73(9):593-602.

12. Momekov G, Momekova D. Ivermectin as a potential COVID-19 treatment [26] from the pharmacokinetic point of view: Antiviral levels are not likely attainable with known dosing regimens. Biotechnology \& Biotechnological Equipment. 2020;34(1);469-474

\section{Tables}

\section{TABLE 1 DEMOGRAPHIC PROFILE OF STUDIED POPULATION}

\begin{tabular}{|c|c|c|}
\hline S.No. & Characteristics & Subjects $(n=306)$ \\
\hline 1. & Age (mean $\pm S D)$ & $34.41 \pm 4.08$ \\
\hline 2. & $\begin{array}{l}\text { Age group (Years) } \\
21-30 \\
31-40 \\
41-50 \\
51-60\end{array}$ & $\begin{array}{l}102(33.3) \\
132(43.1) \\
60(19.6) \\
12(3.9)\end{array}$ \\
\hline 3. & $\begin{array}{l}\text { Gender (n, \%) } \\
\text { Male } \\
\text { Female }\end{array}$ & $\begin{array}{l}204(66.7) \\
102(33.3)\end{array}$ \\
\hline 4. & $\begin{array}{l}\text { Health workers belongs to } \\
\text { Government hospital } \\
\text { Private hospital/clinic }\end{array}$ & $\begin{array}{l}240(78.4) \\
66(21.6)\end{array}$ \\
\hline 5. & $\begin{array}{l}\text { Co-morbidity (n, \%) } \\
\text { Yes } \\
\text { No }\end{array}$ & $\begin{array}{l}48(15.7) \\
258(84.3)\end{array}$ \\
\hline
\end{tabular}

TABLE 2 ASSESSMENT OF KNOWLEDGE OF HEALTHCARE PROFESSIONALS TOWARDS COVID-19, AND IVERMECTIN PROPHYLAXIS

\begin{tabular}{|c|c|c|c|}
\hline S.No. & Particulars & Yes $(n, \%)$ & No $(n, \%)$ \\
\hline 1 & Do you know about COVID-19? & $306(100)$ & 0 \\
\hline 2 & Is treatment of COVID-19 available or not available? & 198(64.7) & 108(35.3) \\
\hline 3 & Have you heard about ivermectin? & $300(98)$ & $6(2)$ \\
\hline 4 & Do you know about its role in pre-exposure prophylaxis for COVID-19? & 288(94.1) & 18(5.9) \\
\hline 5 & Do you know use of ivermectin in COVID-19 is in experimental phase? & 294(96.1) & 24(7.9) \\
\hline
\end{tabular}

$\begin{aligned} & \text { TABLE } \\
& \text { EXPOSED ASSESSMENT OF ATTITUDE TOWARDS IVERMECTIN PRE-EXPOSURE }\end{aligned}$
\begin{tabular}{|l|l|l|l|}
\hline S. PROPHYLAXIS & AMONG \\
\hline $\mathbf{1}$ & Particulars & Yes $(\mathrm{n}, \%)$ & No $(\mathrm{n}, \%)$ \\
\hline $\mathbf{2}$ & Do you think that ivermectin should be used for pre-exposure prophylaxis of COVID-19? & $270(88.2)$ & $36(11.8)$ \\
\hline $\mathbf{3}$ & Do you think it will protect against COVID-19? & $180(58.8)$ & $126(41.2)$ \\
\hline $\mathbf{4}$ & Do you think it will lead to false sense of security, as the drug is in the experimental phase? & $216(70.6)$ & $90(29.4)$ \\
\hline
\end{tabular}

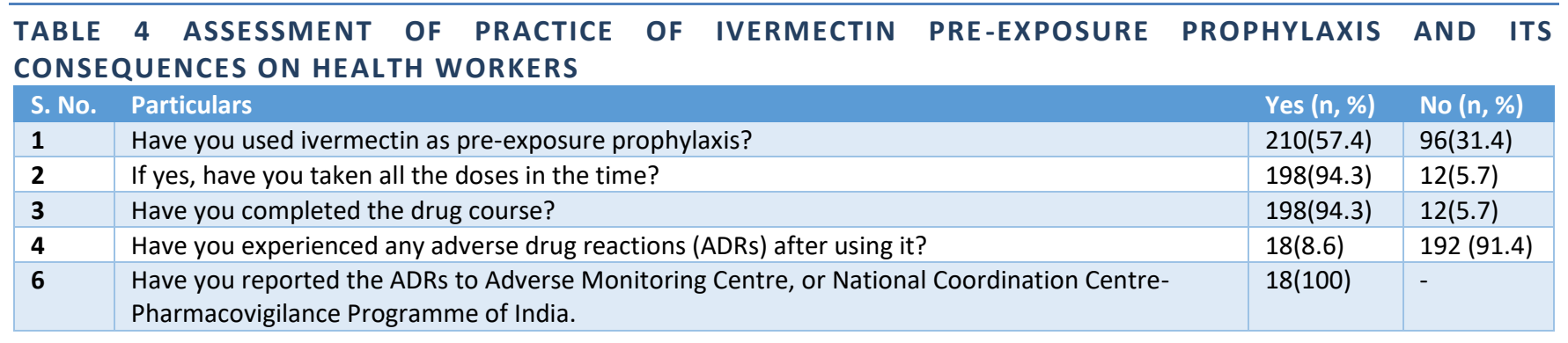




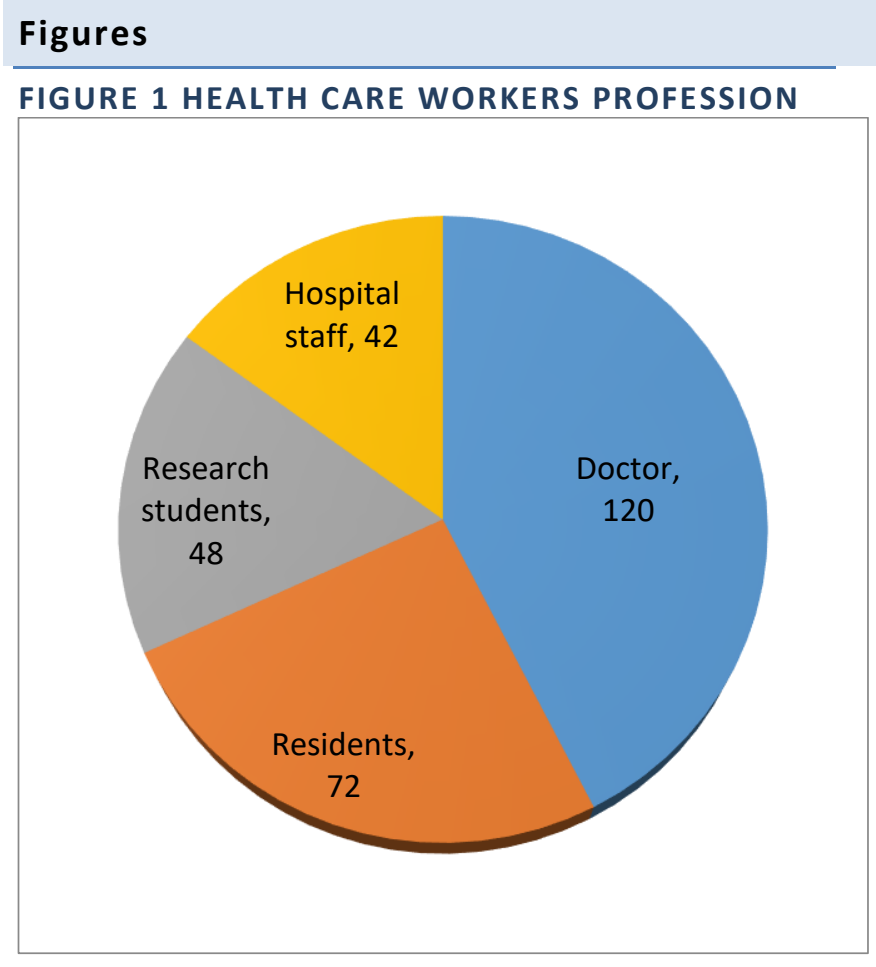

FIGURE 2 CO-MORBIDITIES OF HEALTH CARE WORKERS

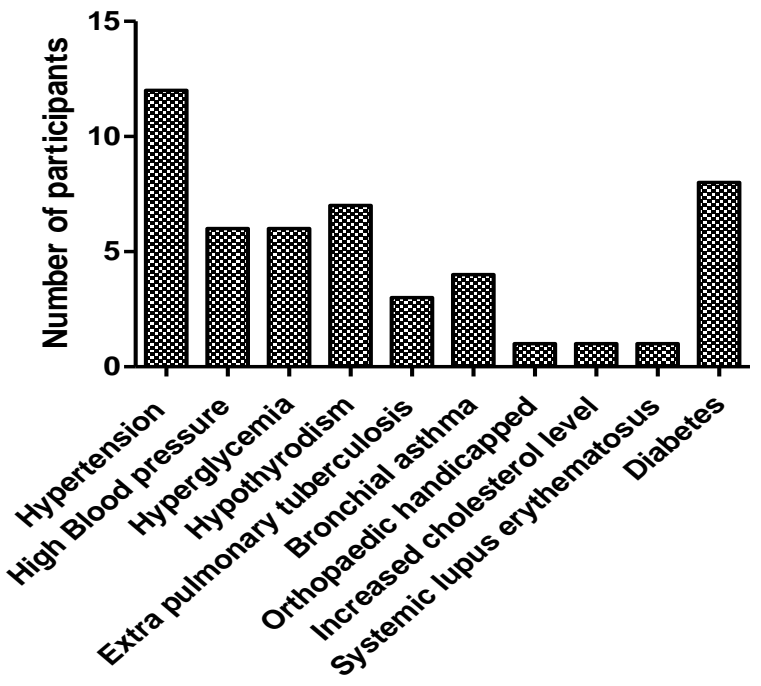

Comorbidities of Health care workers
FIGURE 3 WHAT DO YOU THINK ABOUT THE BENEFIT: RISK RATIO OF USING IT? (MORE BENEFIT; MORE RISK; NOT SURE)

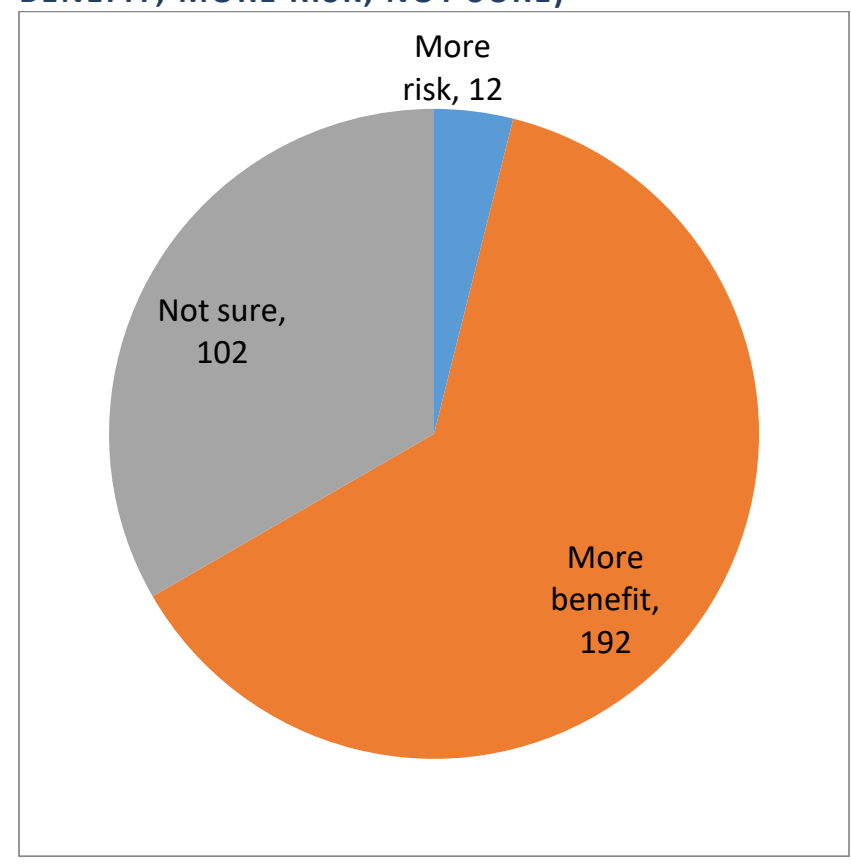

FIGURE 4 ADVERSE DRUG REACTIONS (ADRS) EXPERIENCED BY HCWS

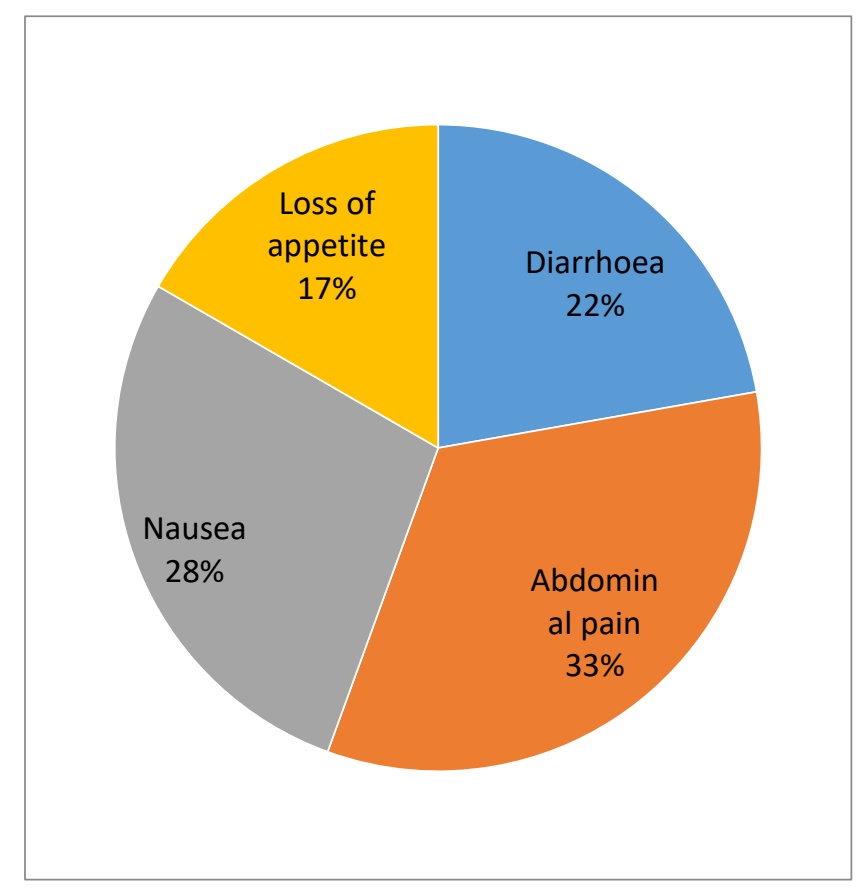

